\title{
Leopoldo Lugones: etimología y poder. Antecedencias y precedencias en La Nación (1923-1925)
}

\author{
Leopoldo Lugones: Etymology and power. Antecedents and precedences in La Nación (1923-1925)
}

Diego Bentivegna

CONICET - Universidad de Buenos Aires - Universidad Nacional de Tres de Febrero, Argentina

\begin{abstract}
Resumen:
El trabajo analiza una serie de artículos sobre cuestiones etimológicas que el poeta argentino Leopoldo Lugones publica en el diario La Nación entre 1923 y 1925. Se trata de un conjunto orgánico de notas de intervención cultural y política que permite, por un lado, avanzar en la plasmación del proyecto filológico esbozado por Lugones en las conferencias de 1913 que serán publicadas bajo el título El payador, y anticipan, por el otro, el proyecto de más largo aliento: el Diccionario etimológico del castellano usual, que irá publicando a partir de 1930 en las páginas de El monitor. Con herramientas provenientes de los estudios glotopolíticos, del análisis del discurso y de los estudios literarios, analizamos las notas -contemporáneas al discurso de Ayacucho y a la fundación del Instituto de Filología de la ciudad de Buenos Aires- insertándolas en otras series textuales presentes en el diario (las notas euríndicas de Ricardo Rojas, las intervenciones de un filólogo profesional como Américo Castro, etc.), pensándolas a la vez en un universo discursivo más amplio y en un momento de alta figuración pública de Lugones. Nuestra tesis principal es que estas notas etimológicas lugonianas representan un gesto glotopolítico fuerte ligado con un modelo homogéneo de Nación, en la medida en que, por un lado, legitiman a partir de tradiciones letradas percibidas como prestigiosas (la griega y la arábiga), una parte del léxico americano, y, por el otro, suponen la puesta en marcha de un proceso de inmunización del objeto lengua con respecto a los elementos provenientes de las culturas indígenas latinoamericanas.
\end{abstract}

Palabras ClaVe: Etimología, Poder, Debates en torno a la lengua, Hegemonías lingüísticas, Americanismos.

\section{Abstract:}

The following paper analyzes a series of press articles on etymological issues, published by Argentine writer Leopoldo Lugones in La Nación from 1923 to 1925. It is an organic whole of sketches aimed at cultural and political intervention, allowing Lugones, on the one side, to go further with his philological project, first essayed in his 1913 conferences, later published in El Payador. On the other side, these notes anticipate the bigger project, his Diccionario etimológico del castellano usual, which he would publish in the pages of El monitor from 1930 on. With critical tools developed in the fields of glotopolitics, discourse analyses and literary studies, these notes -contemporary to the Ayacucho speech and the foundation of Buenos Aires' Institute of Philology- shall be analyzed inserted in other textual series present in the same newspaper (Ricardo Rojas' 'eurindian' notes, interventions by a professional philologist like Américo Castro, etc.), conceiving them at the same time within a broader discursive realm, as well as anchored in a historical momentum in which Lugones' public figure becomes highly present. The main thesis in this paper is that Lugones' etymological sketches represent a strong glotopolitical gesture, bounded to a homogeneous image of the Nation, every time that they, on the one side, legitimate a part of the native Latin American lexicon on the basis of lettered traditions taken for prestigious (Greek and Arab traditions), and on the other, they are bringing up an immunization process for language in face of those items stemming from Latin American indigenous cultures.

KEYWORDS: Etymology, Power, Debates on language, Language hegemony, Americanisms.

1. Entre enero de 1923 y abril 1925 Leopoldo Lugones publica en el diario La Nación una serie de artículos que asumen la forma del apunte o de la curiosidad etimológica y que anticipan el trabajo más sistemático que emprenderá a partir de 1931 en las páginas de El monitorde la educación común, publicado por la Academia Argentina de Letras póstumamente en 1944, bajo el título Diccionario etimológico del castellano usual. Pongo el énfasis en su condición genérica de "apuntes" sobre cuestiones lingüísticas que asumen una modalidad de saber manifiestamente conjetural, diferenciada de otras posiciones que emergen, en el arco temporal en que Lugones comienza a publicar sus notas etimológicas, 
en las mismas páginas de La Nación:la normativa (Ricardo Monner Sans), la euríndica (Ricardo Rojas) y la antropológica, orientada sobre todo hacia el estudio de la toponimia indígena (Martiniano Leguizamón, Roberto Lehmann-Nitsche). Enfatizo también la colocación de las notas etimológicas de Lugones en series textuales más amplias y el modo en que funcionan en el marco de las disputas por la construcción de una posición de autoridad hegemónica en sus complejas relaciones entre gramáticas de Estado y posiciones sobre la lengua esgrimidas desde la sociedad civil (Gramsci, 2013) con respecto al castellano de América y al problema de las lenguas en la Argentina.

Es importante subrayar además la lógica misma de las publicaciones inscriptas en el formato genérico de la "nota" en las páginas dominicales de La Nación y su desclausuramiento (Angenot, 2010: 20), y sumergidas en consecuencia en la totalidad del discurso social (en los límites materiales, en este caso, del diario) en el que proliferan los enunciados que tematizan de una manera u otra la cuestión lingüística. Esta proliferación -y esta dispersión- de los enunciados sobre las lenguas y su inmersión en dominios discursivos más amplios que involucran las esferas literaria, política y científica, aunque enmarcados en el formato que provee el diario, permite observar la construcción de sentido glotopolítico a partir del hecho de compartir un mismo campo discursivo (Maingueneau, 1984: 28) como el diario fundado por Mitre, con sus condiciones de aceptabilidad y la eficacia social que ello supone (Angenot, 2010: 21) con otras posiciones de la época sobre la condición argentina y americana que involucran cuestiones relaciones con las lenguas.

Hay que tener en cuenta como un dato determinante para comprender la formación de ese campo de reflexión filológico-lingüística que en el arco temporal en que Lugones publica sus notas etimológicas en La Nación -es decir, entre 1923 y 1925- se produce un acontecimiento cardinal desde el punto de vista glotopolítico. Me refiero a la fundación del Instituto de Filología de la Universidad de Buenos Aires, impulsado -como sabemos- por Ricardo Rojas, otro de los grandes intelectuales-profesores que llegan desde las provincias del interior a Buenos Aires a fines del siglo XIX y que se inscriben en un principio en el modernismo.

El Instituto es inaugurado el 3 de junio de 1923, con el patrocinio del Centro de Estudios Históricos de Madrid -dirigido por Ramón Menéndez Pidal- y es puesto bajo la dirección de uno de sus más notorios discípulos, Américo Castro (Bentivegna, 2011; Degiovanni y Toscano, 2010), que hará de un diario como La Nación uno de los principales medios de difusión de la nueva orientación ${ }^{1}$. Paralelamente, en el momento en que Lugones comienza su serie etimológica se van materializando proyectos estéticos impulsados por "intelectuales profesores" (Bombini, 2004; Dalmaroni, 2006) que se involucran de manera explícita en la cuestión lingüística, como el programa cultural “euríndico” de Ricardo Rojas - un proyecto que se mostrará como no coincidente en todos sus puntos con el de los filólogos de formación pidaliana que el propio Rojas convoca para dar forma al Instituto- y las posiciones de una "vanguardia" tibia, plasmadas en Proa y, más tarde, en Martín Fierro.

En esos mismos años, la figura de Lugones está en la apoteosis de su reconocimiento público. En 1924, a instancias de Carlos Obligado y con el aval de intelectuales de diferentes generaciones -algunos de ellos, enfrentados a la estética y a la política lugonianas- como Roberto J. Payró, Ricardo Rojas, Enrique Larreta, Horacio Quiroga, Alfonsina Storni, Jorge Luis Borges, Rafael Arrieta, Ezequiel Martínez Estrada y Alberto Gerchunoff, es galardonado con el Premio Nacional de Literatura. Se le otorga el premio luego de su regreso de Europa, donde ha sido invitado especialmente por la Liga de las Naciones a su Asamblea General en la ciudad suiza de Ginebra, junto con intelectuales tan notorios como Henri Bergson o Albert Einstein. El filósofo francés tendrá palabras públicas de reconocimiento para el escritor argentino (Conil Paz, 1985: 307) y será este quien reciba al científico alemán en su viaje a la Argentina al año siguiente, 1925.

Como es notorio, en esos mismos años los tiempos políticos lugonianos se aceleran y se radicalizan. En julio de 1923, el año que se había iniciado con la publicación en enero de la primera entrega de las notas etimológicas que aquí nos interesan, Lugones pronuncia en el Teatro Coliseo la serie de conferencias que se publican ese mismo año con el título de Acción y que propugnan un programa afín al de la Action Française de Maurras y a los fasci mussolinianos (Conil Paz, 1985: 299). El 9 de diciembre de 1924, siempre dentro 
del arco temporal de la publicación de las notas sobre etimología en La Nación, el escritor efectúa en Lima su intervención política más famosa y controvertida, en ocasión del centenario de la batalla de Ayacucho, en la que aboga por una espada que "implementará la jerarquía que la democracia ha malogrado", derivada hacia la "demagogia o el socialismo".

La escalada autoritaria de Lugones -al calor del desencanto de la revolución rusa y del avance de los autoritarismos en Europa a partir de la marcha sobre Roma de Mussolini en 1922- es paralela a su posicionamiento crítico con respecto a las posiciones latinoamericanistas, que se habían potenciado en la Argentina a partir de la fundación de la Unión Latinoamericana, impulsada por José Ingenieros. Un año más tarde del discurso de Ayacucho, en 1925 el latinoamericanismo se revela para Lugones -que retoma sus hipótesis americanistas de 1917, cuando propiciaba la intervención en la guerra europea junto con Estados Unidos, contra la política neutralista de Yrigoyen-, como un problema, ante el que propone un repliegue sobre lo nacional como entidad homogénea, una concepción de soberanía sustentada en la idea de "potencia" argentina, la confluencia con los intereses norteamericanos y la proyección de una unidad regional con Brasil, Uruguay y Paraguay (los mismos Estados que, mucho más tarde, darán origen al Mercosur). En efecto, en ese año, 1924, el autor de La guerra gauch a sostiene, en polémica con los postulados de la Unión Latinoamericana en la que, junto con Ingenieros, participan intelectuales de diferentes latitudes de América, como el mexicano José Vasconcelos y el argentino Manuel Ugarte, que América Latina es una mera “expresión etnográfica” y que "no existe la menor posibilidad de transformarla en unidad política” (Lugones, 1930: 112).

2. Las primeras intervenciones de Lugones con respecto a la etimología en las que nos centramos se inscriben en el marco de esas tensiones entre lo etnográfico y lo político que atraviesan la definición de América Latina, sobre todo a partir del lugar que las tradiciones occidentales y las tradiciones indígenas ocupan en esa definición. En este punto, las notas sobre cuestiones lingüísticas que Lugones publica en La Nación suturan las posiciones sobre la lengua que aparecían desplegadas en El payador con el proyecto del Diccionario etimológico del castellano usual. Significativamente, una de las notas etimológicas (Lugones, 1924b) propone -contra la famosa etimología en "gauderio" sugerida por Daniel Granada en 1890 su Vocabulario rioplatense y las filiaciones indígenas ensayadas por Samuel Lafone y Quevedo en 1898 en su Tesoro de catamarqueñismos y por Rodolfo Lenz en 1910 en su Diccionario etimolójico de las voces chilenas derivadas de las lenguas indíjenas americanas- la filiación arábiga de la voz gaucho (del ar. wash, washe o washi: "bestia salvaje" y, por extensión, "levantisco", "bravío", “arisco", "huraño"), es decir, la pertenencia a un horizonte cultural euroasiático del nombre del sujeto que en las conferencias de 1913 ocupaba el eje en el que se dirimía para Lugones la identidad cultural e histórica argentina (Rodríguez Pérsico, 2006; Dobry, 2010; Bentivegna, 2018).

En el caso de El payador, las hipótesis que allí esboza Lugones en torno a la lengua de los poetas gauchescos le permitía conjurar un fantasma que Ángel Rama nombra como "angustia generalizada de los escritores modernistas respecto a la lengua española” (Rama, 1985: 180) a través de hipótesis generales sobre la condición del castellano de América y su legitimidad con respecto a la variedad asociada con Castilla y, en general, con España. Incluso, en una de las notas en las que La Nación informa sobre las conferencias de 1913, se extracta un fragmento de la conferencia final de Lugones en el que aparece el sintagma "futuro idioma nacional”, cuya fuente debería encontrarse en la gramática de la lengua de los poemas gauchescos. De allí, Lugones había derivado el proyecto de un desarrollo ulterior de los estudios filológicos en la Argentina, que, según su propio planteo, por entonces incluía "dos o tres cátedras de lenguas indígenas, no solo por la importancia que ellas han tenido y tienen en la formación de nuestro idioma, sino para contribuir, con los elementos que poseemos, al progreso de la filología comparada" (Lugones, 1961:359).

En el Diccionario, la postulación de un futuro idioma nacional -el fantasma de las posiciones agitadas en 1900 por Luciano Abeille, que en los veinte siguen siendo objeto de temor por parte de la acción de los lingüistas profesionales que operan desde el Instituto de Filología de la Universidad de Buenos Aires- ya 
se ha borrado por completo. Ese borramiento se ha hecho sobre la base de una serie de conexiones con el léxico indoeuropeo y el de las lenguas semíticas que Lugones anticipa en la serie de notas de La Nación en las que aquí nos enfocamos. El fin es depurar el espacio de la lengua de las diferentes regiones argentinas, con una clara preponderancia de las provincias centrales (con una preeminencia de las provincias de origen de Lugones -Córdoba- y de su familia -Santiago del Estero-) y del Noroeste, es decir, el antiguo Tucumán, más sometidas a la influencia del quechua y el aymara ${ }^{3}$, anclándola en orígenes filológicos que se postulaban más prestigiosos, de ámbito mediterráneo (griego, latín, árabe).

Así, en la segunda entrega dedicada a "antecedencias griegas", Lugones hace explícito su programa glotopolítico:

El patriotismo regional contra el cual protesté en El payador (capítulo VI) por haber poblado nuestra literatura de vocablos que asignan al lenguaje campesino una abundante filiación indígena, sale definitivamente malparado de la confrontación. Mediante el idioma, que es, en suma, la exclusiva manifestación sensible del alma, resultamos completamente latinos; ya que el helenismo redivivo en nosotros, forma cuerpo con la latinidad. Por esto digo "voces de antecedencia griega".

Cabe, y aun con mayor justeza, a todas las lenguas americanas, lo que dije de la quichua en el citado capítulo del Payador: "Como el idioma indígena era inferior en riqueza léxica, o sea en el elemento que con mayor facilidad aceptan las lenguas, y como pertenecía además, a la raza dominada que tan fácilmente se sometió, infiérese sin esfuerzo la penetración castellana en él"; y a vuelta de hoja (pág. 150) cité no menos de diez y ocho casos comprobatorios.

Hablamos, y por lo tanto pensamos y procedemos como aquellos hombres de Roma que fueron y son en su múltiple descendencia la raza inmortal, suprema flor del género humano. (Lugones, 1923b)

El espacio discursivo con el que las notas de Lugones polemizan, designado con la forma nominal desvalorizadora "patriotismo regional", se marca como un espacio "contra" a través de un verbo subjetivo que, más que un hacer cognitivo, releva hacer de orden político ("protesté"). Al mismo tiempo, mediante un trabajo discursivo de autorreferencia que remite como texto fundacional a las conferencias de 1913, se restablece la continuidad entre discursos parciales de un mismo autor (Greimas, 1976: 20) y se construye un imaginario de continuidad temporal y teórica que asigna coherencia y unidad al proyecto etimológico, pensado como parte de un proyecto crítico -y político- más amplio: el de la legitimación de la nacionalidad argentina por filiación latina y por remoción del carácter indígena de los étimos que se presentan como tales.

Ya desde el título, el Diccionario se presenta como un dispositivo "etimológico". El término, sin embargo, es eludido de manera deliberada por Lugones en el título de sus notas de los años veinte. Así, el término "etimología" aparece en el cuerpo de los textos, pero no en el paratexto. Se opta, en cambio, por otros dos conceptos: "antecedencia", para los griegos, y "precedencia”, para los árabes. Si recordamos la distinción que Michel Foucault encuentra en Nietzsche -un autor frecuentado con interés por Lugones desde sus primeros años (Caeiro, 1975) - entre Ursprung (origen) y Herkunft (“procedencia”), la distancia entre las connotaciones del "origen etimológico" y los otros dos términos puede corresponder, a nivel de hipótesis, a una operación que tiende a complejizar las filiaciones que remiten o bien a la alternativa hispánica o bien a la indígena como orígenes únicos, para incorporar un panorama lingüístico-cultural más amplio, y a la vez más profundo en el tiempo. Detrás de lo hispánico, para Lugones, no está solo lo latino, aunque sea por supuesto el componente determinante, sino también otras tradiciones lingüísticas y culturales, como la griega, la germánica y la árabe y, a través sobre todo de esta última y de manera menos potente, con universos culturales importantes en el programa de la filología europea del siglo XIX, como la lengua persa o el sánscrito. En intelectuales como Lugones, que operan en un marco nacional -el argentino- en el que se ha consolidado la alfabetización de masas a través del sistema escolar y en el que se está produciendo la democratización de la palabra impresa a través del desarrollo de la industria editorial y en el que en consecuencia ya no existe el grupo de letrados como únicos "ejercitantes de la letra en un medio desguarnecido de letras" (Rama, 2004: 65), el recurso a la etimología permite consolidar un espacio de saber que se presenta como complejo y oscuro. En todo caso, se trata de buscar en el origen oculto o escamoteado de palabras sospechadas de contener trazos de lenguas indígenas algo del orden del fundamento, en un intento de develar, a partir del uso de las herramientas 
de la filología y de la crítica de las prácticas lexicográficas anteriores (Granada, Lafone y Quevedo, Lenz, Garzón, Segovia), algo del orden de una identidad primigenia, que permita sostener -en la lógica de muchas de las posiciones de los letrados modernistas del mundo hispano- una pertenencia latina ${ }^{4}$.

Nosotros [los argentinos], por nuestra ascendencia latina, que la concurrencia italiana a nuestro suelo robusteció, pertenecemos a las razas de la belleza, y con esto venimos en línea espiritual directa de la Grecia que fue su progenitora. (cit. en Castro Gómez, 150)

3. Es un panorama que hay que remitir a operaciones como las que lleva adelante la filología del siglo XIX, en especial sobre la base del trabajo de Ernest Renan y sus posiciones sobre la preeminencia de las lenguas de civilización, es decir, las lenguas indoeuropeas y las lenguas semíticas - por sobre las lenguas de los pueblos "salvajes", entre los que el erudito francés incluye, por supuesto, a los indígenas de América (Olender, 2005; Said, 2004; Esposito 2009b)-. Para Renan, en efecto, las razas lingüísticas nobles se reducen a la aria y a la semita, aunque ellas no se encuentran en una situación equivalente. Mientras el ario está abierto, según Renan, a los desarrollos de la ciencia, el arte y la política, el semita se repliega en sí mismo, no está en condiciones de pensar lo múltiple y se cierra con respecto al porvenir (Esposito, 2009b. 69). De todos modos, para el sabio francés arios y semitas, a diferencia de las "razas inferiores" de África, América y Oceanía, nunca han descendido a la barbarie, del mismo modo en que ninguna raza "salvaje" ha pasado a un estado de civilización. Se trata de un pensamiento cuyas huellas discursivas en los intelectuales argentinos, incluso en aquellos de participación progresista, son fuertes. Recordemos, sin ir más lejos, que todavía en 1919 José Ingenieros, compañero de las aventuras ultraizquierdistas de Lugones en La montaña y para mediados de los veinte -como dijimos más arriba- ya en una clara posición latinoamericanista, afirmaba que

La nacionalidad argentina no está formada por indios, sino por descendientes de europeos, y la experiencia enseña que las únicas regiones del mundo que merecen el nombre de civilizadas cuentan en su población un noventa por ciento de sangre europea. (cit. en Terán, 1979: 113)

En la estela de Renan y de la contraposición que plantea entre pueblos "civilizados" y pueblos "salvajes", Lugones "rapta" las voces de una filiación carente de escritura y cuyo prestigio está en disputa, voces asociadas con el indio visto desde la perspectiva de las elites gobernantes como enemigo histórico en la consolidación del Estado argentino, para reinscribirlas en el campo de dos lenguas prestigiosas por su tradición cultural y letrada, a diferencia de lo que percibía en las tradiciones orales americanas, una aria (el griego) y otra semita (la arábiga).

Uno de los postulados más fuertes de Greimas es el de considerar, por hipótesis, que todo discurso de las ciencias humanas obedece a reglas de organización narrativa y asume la forma de la busca de un "objeto de valor" (Greimas, 1976: 11). En la medida en que el objeto es, en este caso, un saber determinado, que afecta a un sector del léxico del castellano americano, el discurso científico se presenta como una "aventura cognitiva" que explicita su trama narrativa a través de la historia de las palabras y provee de esta manera un relato que legitima los orígenes culturalmente altos de las naciones del continente.

Dos de las notas de Lugones están dedicadas a las "antecedencias" griegas y ocho a las "precedencias árabes". Es sintomático que Lugones inicie su serie con exploraciones en torno a los antecedentes en lengua helénica del léxico americano, antecedentes que se ligan con la postulación de lo griego clásico desde el Prometeo de 1910 como fundamento de la nacionalidad argentina. Hay que tener en cuenta que la misma página cultural de La Nación el año anterior al inicio de la serie etimológica (más específicamente, el 28 de mayo de 1922), Lugones había publicado la traducción íntegra al castellano del primer canto de la Ilíada, un proyecto que el autor de La guerra gaucha insertaba, desde sus primeras palabras, en un imaginario patriótico que lo une a las series del Centenario de 1810 y $1816^{5}$. 
En sus notas sobre precedencias griegas, Lugones comienza a desmarcarse del trabajo de los etimologistas que operaron hasta ese momento, remontándose para ello a las crónicas de la conquista:

más de un cronista recogió como americanas, voces oídas a españoles oriundos de regiones cuyas formas léxicas desconocía, iniciándose entonces la confusión y arbitrariedad de atribuciones y de etimologías peculiares a las colecciones de americanismos. La variedad dialectal, no menos que la diversidad de las influencias étnicas en España, concurrieron poderosamente al fenómeno, y éste quedó patente en obras de grande importancia como la Historia natural de Oviedo, o los léxicos organizados para facilitar la predicación. Así se nota el aumento de castellanismos pasados a la quíchua y al guaraní, cuanto más modernas van siendo las colecciones. (Lugones, 1923a)

Incluso -y sobre todo-, opera desmontando las etimologías aceptadas por el Diccionario de la Academia; para ello, Lugones apela a ideologemas (Angenot, 1981: 179) que enfatizan no sólo la "precedencia" temporal con respecto a la conquista, sino también el carácter general de su difusión en el territorio americano. La voz tamal, por ejemplo, de uso extendido en todo el Noroeste argentino, no es para Lugones una voz de origen "mexicano", como proponía el Diccionario de la Real Academia, "queriendo decir, probablemente, azteca", sino que es "de indudable procedencia arábiga", presente ya en el castellano de los conquistadores y difundida, además, en toda América:

Generalizada desde Méjico y Cuba al Río de la Plata, esta difusión excluye, como sabemos, el origen americano. Es sencillamente el árabe "tamal", guiso. (Lugones, 1923e)

Las notas presentan definiciones de voces que orientan argumentativamente la atribución arábiga con la que cada secuencia etimológica concluye. Así, el escritor cordobés da una definición de la voz "simbol”, una de las tantas voces del castellano distribuido en la región central, como "una alta gramínea parecida al trigo y a la cebada, aunque de caña o paja más elástica, larga y fuerte; por lo cual la emplean mucho en techar ranchos y carretas" (Lugones, 1925a). En la edición de 2008 del Diccionario del habla de los argentinos, la voz se define como "Planta perenne de la familia de las Gramíneas, de uno o dos metros y medio de alto, empleada como pastura natural" (DHA, 2008, 579). Si confrontamos esta definición lexicográfica actual con la definición que da Lugones en su nota, la comparación con el trigo y la cebada -eminentemente euroasiáticas- que el escritor cordobés plantea como un rasgo importante de su definición anticipa, en este caso, la asociación de la voz argentina con otras arábigas que participan del campo semántico del cultivo del trigo.

A su vez, las notas suelen señalar el punto polémico o problemático, el obstáculo que permite desarrollar una explicación etimológica alternativa a la que presentan no solo el Diccionario académico, sino también la memoria del trabajo de los lexicólogos “americanistas", que en los años inmediatamente anteriores estaban representados, al menos en el Cono Sur, por los vocabularios de Lafone y Quevedo (1898), Lenz (1910) y Tobías Garzón (1910). Muchas veces Lugones alude al trabajo de estos lexicólogos, sin necesariamente nombrarlos:

La voz es quichua para todos nuestros lexicólogos, pero su difusión en el Plata, Chile, Perú, Colombia y Brasil, prueba lo contrario. (Lugones, 1924d)

Finalmente, las notas concluyen comparando las voces puestas "al bando" con voces griegas o arábigas, con la inclusión en muchos casos de fuentes eruditas poco frecuentadas en nuestro país, como los trabajos de John Seiden Willmore sobre el árabe de Egipto o los de Reinhart Dozy sobre el árabe de la península ibérica "En árabe de Egipto (J. Seiden Willmore, Spoken Arabic of Egypt), "kesh" es paja y barro amasado con ella para formar adobes" (Lugones, 1924d).

En muchos casos, se modaliza la conexión entre el término americano y el arábigo como una mera conjetura:

Sin pretender nada, advierto que en árabe de Berbería, es decir del Norte africano, y con ello, vinculado a España, directamente, muchos lugares altos llámanse tecoroni, takeruna: formas que Dozy (Recherches, Hist. Lit. Esp., T. II, pág. 43, 
nota) supone compuestas por el castellano “corona” y el prefijo beréber “te”. Eran fortalezas construidas en picos roqueños, y los "tacuruces" son verdaderos reductos o fuertes cónicos de las hormigas. (Lugones 1923e)

En algunos momentos, la posición de Lugones se plantea de manera tajantemente asertiva. En la mayoría de los casos ("Sin pretender nada, advierto que mugido es, exactamente, "jauár" en árabe”, Lugones 1924d, con respecto al antecedente árabe de jaguar como alternativa al tupí-guaranítico), sin embargo, lo que básicamente hace la nota, que asume la lógica suspendida del discurso entimemático (Angenot, 1981: 173), es mostrar la conexión fonética y de sentido entre la voz americana cuya etimología se propone y la voz arábiga o griega que se hace correlacionar con ella. Es habitual, sin embargo, el paso de la conjetura en cuanto a la atribución etimológica al énfasis en la refutación de las posiciones que Lugones identifica como americanistas. Así, por ejemplo, la voz "simbol”, a la que aludimos más arriba, es remitida por Lugones a dos voces arábigas: "sombol”, que "designa al jacinto o tulipán”, y “sumbul”, espliego, que a su vez, si creemos en la reconstrucción propuesta por el escritor cordobés, proviene del diminutivo latino "spiculum". "Por último, espiga, genéricamente hablando, es 'simbol', lo cual desvanece todas las conjeturas de nuestros lexicólogos americanistas”. (Lugones, 1925a, VII)

4. Las notas muestran un proceso, en el que Lugones acepta errores y se corrige a sí mismo. Desarrolla además explicaciones ad-hoc sobre cambios fonéticos y desplazamiento de sentido, e incluso, de un artículo a otro, se corregirá a sí mismo ${ }^{6}$. En los diferentes artículos de la serie, Lugones moviliza herramientas filológicas y lingüísticas que le permiten obtener conclusiones conjeturales novedosas y, en última instancia, disruptivas en cuanto a las antecedencias previsibles. Es evidente que la gran mayoría de las "antecedencias" que Lugones propone en las notas están atravesadas por dos rasgos: la novedad o imprevisibilidad, puesto que las filiaciones que conjetura no se encuentran en los diccionarios anteriores, y el carácter en general provisorio de la relación entre voces que las notas proponen. El efecto es el de una exploración etimológica en torno a la lengua que pide ser leída desde un lugar diferente del lugar en que la tradición filológica lee la cuestión de los diccionarios.

Hay una zona de la glotopolitica (entendida como estudio de las intervenciones en el espacio público del lenguaje que asocia ideologías lingüísticas con posicionamientos sociales: Arnoux y Nothstein, 2014: 9) que los escritos de Lugones sobre las lenguas permiten interrogar. Es una zona de importancia urgente en la reflexión contemporánea sobre lo político, y que sería bueno plantear con fuerza en la agenda de discusión glotopolítica. Me refiero a los modos en que los discursos públicos como el que estamos abordando plantean relaciones entre lenguajes, vida y política, es decir, a sus articulaciones biopolíticas. Me apoyaré, en este punto, en la noción de inmunidad como contracara de la communitas (Esposito, 2005, 2009 a y b), y la interrogaré desde algunos planteos en torno a la cuestión de la pasión de lo real y las formas de depuración y de sutura, que Alain Badiou piensa como uno de los meollos de lo que denomina "el siglo". Un siglo que, en la Argentina, desde el punto de vista de la historia de las articulaciones entre literatura, lengua y política, puede pensarse como un siglo "lugoniano", que se inaugura en 1913 con las conferencias en el Teatro Odeón.

La primera nota de Lugones retoma las conferencias sobre el poema de Hernández y afirma que:

Aquel estudio especial de la poesía gauchesca, en especial del Martín Fierro, engendró un proyecto de diccionario etimológico del castellano usual, para el que tengo estudiadas ya más de tres mil voces. Iré eligiendo algunas de las más interesantes con propósito de amena vulgarización. (Lugones, 1923a)

El querer-hacer etimológico - que comienza a desplegar un programa narrativo que organiza modalmente el conjunto del discurso (Greimas, 1976: 19) - se plantea como un acto en sí mismo, en el que sujeto al principio está ausente -lexicalizado en el verbo "engendrar", que se inscribe en el campo semántico de la filiación, pero en el mismo enunciado se marca más tarde como sujeto de una acción claramente cognitiva ("tengo estudiadas más de tres mil voces") y de una acción divulgativa ("amena vulgarización”), mientras que la dimensión polémica, que el componente central de la acción discursiva de Lugones, no se explicita. 
Así, las notas etimológicas que se irán publicando en La Nación en diferentes momentos de la década del 20 implican, desde la perspectiva abierta por el propio Lugones al inicio de la serie, un adelanto del proyecto de Diccionario etimológico. La acción etimológica se presenta de manera explícita, en una filiación con algunas posiciones esgrimidas por los intelectuales modernistas como Rubén Darío y José Enrique Rodó (Castro Gómez, 1996: 132). como "reacción latina", es decir, como una acción sustancialmente polémica en relación contra posiciones que Lugones no explicita en términos de nombres propios sino a partir de una forma nominal con cierto tono despectivo:

El patriotismo regional contra el cual protesté en Elpayador (capítulo VI) por haber poblado nuestra literatura de vocablos
que asignan al lenguaje campesino una abundante filiación indígena, sale definitivamente malparado de la confrontación.
Mediante el idioma, que es, en suma, la exclusiva manifestación sensible del alma, resultamos completamente latinos; ya que
el helenismo redivivo en nosotros, forma cuerpo con la latinidad. Por esto digo "voces de antecedencia griega". (Lugones
1923b)

No estamos, en consecuencia, solo ante un discurso puramente cognitivo, sino también ante un discurso con una dimensión polémica explícita, que se inscriba en la lógica de los discursos agónicos (Angenot, 1981: 34), lo que supone un contra-discurso antagónico implicado en su trama y la presencia fuerte y explícita de enunciador. Se da forma así a lo que proponemos pensar como un modo inmunitario de operar sobre el corpus de la lengua. Si la communitas se caracteriza por la libre circulación de lo común, del munus, la immunitas desactiva esa dispersión, "reconstruyendo nuevos confines protectores hacia el exterior del grupo y entre sus propios miembros” (Esposito, 2009a: 3)

Los vocablos de que en estos artículos me ocuparé son americanismos, o, mejor dicho, arcaísmos para el castellano peninsular, aunque dejarán de ser una y otra cosa, no bien les descubramos una etimología arábiga: con lo cual resultará enriquecido el común patrimonio léxico. Insisto en que las voces puramente americanas son muy pocas; y en estas cuantas que examinaré, podrá observar el lector la abundancia de pretendidos quichuismos. (Lugones, 1923c)

Ante la disrupción que implica la heterogeneidad asociada con las variedades autóctonas americanas, que por ejemplo Ricardo Rojas enfatizaba en los capítulos sobre filología americana de Los gauchescos (1917) que prosigue en las notas de la serie de Eurindia que publica precisamente en La Nación cuando se producen las intervenciones etimológicas de Lugones-y aquello que no se percibe en las notas pero que otros artículos de la época tematizan (la presencia heteroglósica de grandes contingentes inmigratorios), la estrategia es una apelación no tanto al origen como comienzo absoluto, sino a la "procedencia" o la "antecedencia".

No se trata, para Lugones, de pensar la especificidad de las variedades americanas a partir de la noción de “americanismo". Era lo que el autor de La guerra gauch a podía encontrar en los ensayos euríndicos de Ricardo Rojas, uno de los cuales, publicado el 29 de octubre de 1922 en las páginas culturales de La Nación, tan sólo dos meses antes de que comenzara la serie etimológica", dedica un espacio importante a las lenguas indígenas que sobreviven en el territorio argentino y a sus aportes léxicos, que permiten proyectar continuidades culturales con el resto de América más allá del hecho de compartir la lengua española.

Las lenguas indígenas han sido no solo un factor de enriquecimiento, modificación y color local del castellano de América, sino un acervo de tradiciones folklóricas antiquísimas y un nexo de solidaridad continental por sus parentescos americanos. (Rojas, 1992: I, 32)

Lugones podía hallar también una reflexión sobre los americanismos en los estudios de un lexicógrafo académico como Miguel de Toro y Gisbert, que en ese mismo 1922 había dedicado un extenso artículo incluido nada menos que en el Boletín de la Real Academia Española-, a la terminología de La guerra gaucha, y que publica un volumen entero dedicado a la cuestión de los americanismos. En la introducción de ese volumen, Toro y Gisbert enfatiza el carácter "desviado" del español de América, y da por hecho "que se habla en todo América española una jerga corrompidísima” (Toro y Gisbert, 1912: 1). La solución, para Toro y Gisbert, radica en potenciar el componente hispánico de la lengua americana, asociado con la hegemonía de la norma castellana. Es preciso, pues, que los escritores americanos "se resuelvan a arrancar de su estilo (no digo 
de su vocabulario) todo cuanto pueda chocar a los oídos españoles", que abandonen "el olímpico desdén” por la gramática y que, en síntesis, "reanuden la tradición española, que vuelvan a beber de la purísima fuente de los clásicos españoles y que renuncien por algún tiempo a la imitación estéril del francés”. (Toro y Gisbert, 1912: 50)

Para asuntos "puramente hispanoamericanos", afirma Toro y Gisbert, "el mejor centro ha de ser España" (1912:61), como parámetro en la construcción y en la fijación de la lengua literaria que contrapone a las tesis de Luciano Abeille, que caricaturiza con un argumento claramente clasista

Conque o negamos el desarrollo de la República Argentina o hemos de creer en ese admirable porvenir en que todos los argentinos han de hablar como los aguadores y las amas de cría de la Península. (Toro y Gisbert, 1912: 12)

Asumir como válidas las afirmaciones de Toro y Gisbert implica aceptar de hecho una relación de periferia en relación con la forma no marcada representada por las variedades del castellano del centro-norte de Castilla, sino de dar un paso más allá en la que es la idea misma de americanismo ${ }^{7}$. Si el Diccionario de la Real Academia define en su edición de 1914 "americanismo" como "vocablo o giro propio y privativo de los americanos que hablan la lengua española”, la operación glotopolítica de Lugones consiste en reponer, para impugnar la noción, la cuestión de las filiaciones.

Su objeto es llegar a una suerte de momento originario y pleno, incontaminado, que, de acuerdo con los planteos de Badiou, permitiría pensar la continuidad entre los planteos de Lugones y los "ámbitos del pensamiento fascista" (como ciertas derivas etimologistas de Heidegger) para el que el "hombre nuevo" es básicamente la restitución de un hombre antiguo. "La depuración es en realidad el proceso más o menos violento de retorno a un origen desvanecido" (Badiou: 2005: 91). La intervención glotopolítica de las notas radica en la reposición de la filiación originaria mediante la disipación de lo inauténtico ${ }^{8}$. Continúa operando en el imaginario de intelectuales modernistas como Lugones la memoria letrada, para la que el habla cortesana se opone a "la algarabía, la informalidad, la torpeza y la invención incesante del habla popular, cuya libertad se identificó con corrupción, ignorancia, barbarismo" (Rama, 2004: 74). En definitiva, las filiaciones árabes y griegas permitirían controlar esa tendencia al exceso a través de un aferrarse a un relato de los orígenes y demostrarían la persistencia en América de una tradición olvidada en su mayor parte en Europa y, en este sentido, de un modo más originario y legítimo de participación en un universo cultural que va de Grecia a los grandes logros de la cultura árabe, sustentado en la lengua.

5. Para pensar las disputas en torno a la legitimidad de los estudios sobre las lenguas en la Argentina, es significativo reponer la reacción de Lugones ante la publicación en abril de 1924, siempre en La Nación, de un artículo en dos entregas de Américo Castro acerca del "dialecto argentino". Castro, que por entonces es invitado a dar conferencias en Nueva York y París (Peña, 1973), se pronuncia con la autoridad de haber sido el primer director del Instituto de Filología de la Universidad de Buenos Aires. Anticipando las conclusiones a las que en teoría llegarían los estudios emprendidos por la flamante institución, el filólogo español plantea como objeto de discusión no tanto un supuesto "dialecto argentino", cuya existencia es una hipótesis que termina descartando, sino el castellano en sus variedades populares y, sobre todo, urbanas.

En esas dos entregas, Castro sostenía, entre otros planteos, lo que considera sin medias tintas como el "empobrecimiento del español de América", confrontado obviamente con la variedad culta castellana. Este "empobrecimiento" produciría no estrictamente una serie de "dialectos" nacionales, como el eventual "dialecto argentino", un concepto que Castro objeta comprensiblemente para evitar que se retome la posibilidad de la afirmación hipotética de algo tal como una lengua nacional argentina de carácter relativamente autónomo, sino más bien el "vulgarismo o popularismo hispánico o hispanoamericano". "No se trata de "peculiaridades" (un término, lo sabemos, caro a Castro) que puedan caracterizar un dialecto, sino de momentáneos olvidos de la gramática, que los maestros podrían corregir con menos esfuerzo del que ha 
costado restaurar las eses finales de las sílabas", afirma Castro en la segunda entrega, del 30 de abril (Castro, 1924b). Allí Castro traza algunos rasgos del castellano vulgar en el plano del vocabulario, "zona movediza, en la que cada época y cada influjo de la cultura pone su huella", con el objetivo de demarcar el espacio de la "Lengua culta", concebida como un "órgano de internacionalidad". A través de ella, "se irán suprimiendo los restos de la rusticidad y del vulgarismo tradicionales, y se atenuará la manía galicista y populachera” (Castro, 1924b).

En cuanto al léxico del Río de la Plata, Castro plantea algunas características generales, como el "empobrecimiento por olvido" de sinónimos, la presencia de neologismos, de galicismos, italianismos e "indianismos" - un marcador no usado por la RAE, pero sí por otros diccionarios importantes de la época, como el Diccionario Sopena publicado en Barcelona en 1917, que lo define como "idiotismo o modismo especial del lenguaje indio"- como baquiano, llapa, macana, bagual y chancho.

En uno de los artículos incluidos en la primera publicación del Instituto de Filología de la Universidad de Buenos Aires bajo la dirección de Castro, el prestigioso lingüista alemán Max Leopold Wagner insistía también en la cuestión de los “indianismos" presentes en el español americano. Para Wagner, cuyas posiciones en este artículo serán determinantes para la elaboración de la tesis del andalucismo del español de América (Del Valle, 1998; Valdez, 2015: 185), esos elementos, que propone comparar con los restos léxicos de las diferentes lenguas prerromanas presentes en el latín, suponen la presencia de un substrato étnico que altera la homogeneidad cultural hispano-latina, en la medida en que son elementos en general del campo de la agricultura, la fauna y "los modos de vida distintos de los españoles" (Wagner, 1924: 80). Es precisamente esta serie de "indianismos" propuesta por Castro -asociables, como hemos dicho, con universos culturales "otros" con respecto a los europeos- lo que objeta Lugones, en especial la voz bagual. El autor de El payador rechaza su procedencia de alguna lengua americana, sea la lengua "pampa”, sea el guaraní, filiación "indiana" que, para pesar seguramente de Lugones, será refrendada por el Diccionario de la RAE en su edición del año siguiente, 1925, que la presenta como voz proveniente del "araucano" cahual, apropiación a su vez del castellano caballo?.

Roberto Esposito recuerda que, para uno de los grandes teóricos del fascismo, el jurista alemán Carl Schmitt, nomos "tiene como significado inicial la separación" (Esposito, 2009a: 7) ${ }^{10}$. Para Lugones, si entendemos por "indianismos" - "vocablos procedentes de las lenguas de indios americanos", la cuestión requiere una intervención reparadora, cercenar la lengua del mismo modo en que la espada cercena el cuerpo social, "sin la menor intención polémica y solo a título de contribución".

A semejanza de muchos americanismos que tengo estudiados en mis artículos anteriores ("Voces americanas de procedencia arábiga”), "bagual” resulta de una confluencia bajo-latino-arábiga tan convincente como interesante. (Lugones, 1924c)

Lugones retrotrae la voz americana al provenzal y a diferentes variedades del árabe. La primera fuente es provenzal: bagás, bagat, que a su vez proviene del latino vagans, vagabundo. Junto con la que opera una "decisiva" voz arábiga para determinar la fonesis y la acepción de bagual, caballo arisco, cerril. Mulo y mula, en Argelia, es baglá, cuyo plural es bgal, y en Marruecos, begla y bagal. Ello explicaría el sentido, por extensión, de bagual, como animal reacio a la captura. Como en Castro, en Lugones hay una impugnación de la existencia de un "dialecto argentino", en la medida en que las variedades locales pueden exhibir una prosapia que conservan con mayor eficacia que las peninsulares:

Casi todo el pretendido "dialecto argentino" es, así, buen castellano, y aún del mejor, como que se trata del castellano de la Conquista: el idioma de los héroes, no atildado todavía por el humanismo. De ahí las diferencias actuales con el idioma peninsular, o español propiamente dicho.

No hay, pues, tales dialectos, sino, para bien de todos, un solo y magnífico idioma, que al ser el verbo de veinte naciones, sin contar sus vastas zonas de influencia en la Europa Oriental, Asia y África, constitúyenos desde luego uno de los más vastos imperios espirituales. 
Toda limitación, consista ella en el dominio metropolitano, perfectamente quimérico, por lo demás, o en la autonomía comarcana de un mal entendido patriotismo, arriesga el malogro de tan precioso bien. La verdadera obra superior consistiría en iniciar cuanto antes el balance científico del tesoro. (Lugones, 1924c)

6. La enmienda de Lugones11 al "indianismo" de Américo Castro motiva, a su vez, la publicación en La Nación de un artículo de Paul Groussac, ya anciano, con el título de "Sobre cuestiones de filología americana”. En él, Groussac reivindica para sí el mérito de haber señalado en su momento la inclusión errónea de "chancho" entre los americanismos, ya que el término aparece registrado en la reproducción del habla de los sectores populares de la península en texto del Siglo de Oro escritos y publicados en España.

La intervención de Groussac se apoya en la autoridad que le otorga el hecho de haber escrito sobre la cuestión del léxico de las variedades americanas tempranamente, en el artículo "A propósito de americanismos", publicado en 1900 en los Anales de la Biblioteca. Ese texto, en efecto, señalaba dos caminos para el desarrollo de una futura disciplina filológica en la Argentina que, en muchos aspectos, Lugones retoma en sus artículos de los años veinte: la impugnación de falsos americanismo léxicos y de la falta de rigor en la inclusión de voces cuyo origen aparente residiría en lenguas americanas poco o nada conocidas (como el caso del Tesoro de catamarqueñismos de Lafone, cuyas filiaciones en la hipotética lengua cacana de los Valles Calchaquíes -anterior a la incorporación de esos territorios al imperio incaico- era objeto de los densos sarcasmos de Groussac), y la necesidad de articular una metodología histórica seria, apoyada en el conocimiento de las lenguas arias y semitas y en la familiaridad con los documentos coloniales americanos.

Lo importante del nuevo artículo de Groussac es que señala al mismo tiempo no sólo el desconocimiento específico del "filólogo español Américo Castro", sino también la "ristra de divagaciones metafísicas" y "un estado de ignorancia, ya que no de mala fe (compartido, al parecer, por el profesor Castro), que se calificaría de inaudito...", que le achaca a Lugones. En efecto, si en su artículo de 1900 Groussac reaccionaba ante la proliferación de etimologías poco rigurosas que se apoyaban en parecidos fonéticos circunstanciales y propugnaba, en cambio, por historias documentadas del léxico americano, en 1925 podía presentar un modelo concreto de trabajo alternativo al de los letrados autodidactas como Rojas o Lugones -que, pese a sus programas divergentes, podían ser vistos por el anciano director de la Biblioteca como avatares de los trabajos de Lafone y Quevedo- y a los filólogos como Castro. Ese modelo de investigación filológica propuesto por Groussac no es el de las nuevas camadas filológicas formadas en el seno de la escuela histórica de Menéndez Pidal ni lo son tampoco, por cierto, las "divagaciones" etimológicas lugonianas. Groussac se inclina en cambio por la tradición de los estudios lingüísticos en lengua alemana, representados por

un filólogo de verdad, acaso el único existente en América del Sur: me refiero al Dr. Rodolfo Lenz, autor de un Diccionario etimológico de las voces chilenas derivadas de lenguas indígenas americanas, obra de excelente doctrina filológica, que ha conquistado autoridad universal en la materia. (Groussac, 1924) ${ }^{12}$

De esta manera, desde su autoridad patriarcal como director de la Biblioteca Nacional, Groussac interviene en los debates por la formación de un campo de estudios filológicos en la Argentina señalando como modelo el de los estudios históricos de la escuela alemana encarnados en Lenz, a quien considera que tanto Lugones como Castro ningunean, o, al menos, soslayan. Es asimismo el trabajo filológico de Lenz en Chile lo que Rojas postula en Eurindia como modelo para el estudio de la influencia del quechua y del guaraní, "cuyas voces se cuentan por centenares en el castellano de la Argentina, sin olvidar su influencia en la prosodia, perceptible en el canto provinciano". (Rojas, 1992: 31)

Justamente, el Diccionario de Lenz se sostenía en un proyecto cultural, y en última instancia político, antagónico con respecto al que asume Lugones. En efecto, para el profesor alemán el estudio del español popular chileno implica preguntarse "cuántas cosas tuvieron que aprender los orgullosos castellanos de los pueblos indios, a quienes tanto despreciaban” (Lenz, 1910: 41). Se verá así "cuántos útiles conocimientos 
del pueblo chileno actual son debidos al indio" (Lenz, 1910: 41). Distanciándose, a su vez, de lo que en 1938 Amado Alonso, director entonces del Instituto de Filología, calificará como la "teoría indigenista" del profesor chileno-alemán (Ennis y Pfänder, 2013: 132) y enmendando la observación “indianista” de Castro, Lugones marca un espacio para la reflexión filológica que no coincide, por su radicalidad, con el programa que se esboza desde el Instituto de Filología. La "verdadera obra superior" en ese ámbito no consistiría en el estudio de las diferentes variedades y su contraste con la variedad culta castellana, como tampoco en el trabajo sobre el sustrato indígena del castellano de América, sino más bien en la exploración etimológica del "tesoro" de la lengua que muestre sus conexiones indisolubles con los grandes grupos lingüísticos prestigiosos, tanto arios como semitas, y conjure el elemento desestabilizador asociado con la acción y la persistencia de las diferentes variedades de las lenguas indígenas. Como mostramos en otro lugar, las conferencias de Lugones son, también, una toma de posición explícita desde un punto de vista político sobre lo que entonces se planteaba todavía como la cuestión de la lengua, que en los años veinte, los años de publicación de la serie de artículos que nos interesan en este trabajo, asumen nuevas inflexiones. El 18 de marzo de 1925, por ejemplo, La Nación recoge en un lugar privilegiado -la parte superior de la portada- un recuadro con el título “D. Ramón del Valle Inclán habla del futuro idioma argentino", donde se reproducen palabras de quien era considerado como el prosista más alto del modernismo en castellano, dichas ante un grupo de intelectuales en Vigo en un ambiente íntimo, que reavivan el fantasma de la independencia lingüística -que Lugones mismo había abonado en el discurso que dedicada en 1916 a la memoria de Rubén Darío-, propugnado en 1900 como se sabe, por Luciano Abeille, denostado por Castro en "Sobre dialecto argentino":

El nuevo idioma -habría afirmado Valle-Inclán según el cronista de La Nación- será el producto de la fusión de todos los idiomas de las razas que pueblan sus campos y montañas, y esto se efectuará cuanto más rápidamente se practique la sentencia de Alberdi: gobernar es poblar, sentencia digna de Tácito. (Anónimo, 1925)

El espacio del diario permite leer las tensiones y las disputas, en algunos casos explícitas, con otras posiciones sobre las lenguas y la condición de la filología en la Argentina. La postura de Luciano Abeille, por ejemplo, había sido explícitamente recordada como insostenible en "Sobre dialecto argentino", de Américo Castro, una de las primeras intervenciones pensadas desde el ámbito de una formación universitaria sistemática para contraponerse a la tradición del intelectual autodidacta del modernismo, un producto, dice Rama, de la "confusa y tumultuosa democratización" que está en condiciones de postular una visión más libre y más caótica y "salvaje" (Rama, 2004: 186) de un área específica del saber, en este caso el área del saber sobre las lenguas.

Puede pensarse que el conjunto de los primeros gestos del Instituto de Filología de la Universidad de Buenos Aires dirigidos por el filólogo español está orientado a conjurar las posibilidades de un idioma nacional de los argentinos que había sido sostenida en 1900 por Abeille. Así, por ejemplo, en la primera de las publicaciones del Instituto, que reúne artículos, como hemos visto, de Max Wagner, de Ramón Menéndez Pidal y de su joven discípulo Tomás Navarro Tomás, el texto introductorio firmado por Castro que reproduce parte de los artículos sobre dialecto argentino- reconoce el interés tradicional de los estudios lingüísticos en la América hispana, que en la Argentina asume, tal vez pensando en intervenciones como las de Rojas o Lugones, un "vago sentimiento nacionalista" que, para Castro, "en ningún caso llega hoy al extremo que alcanzó el libro del francés Sr. Abeille” (Castro, 1924: 7). Por su parte, el maestro de la filología en lengua española se detenía todavía en la refutación de las hipótesis del estudio de Abeille, conveniente tergiversadas

La tesis lanzada por Juan María Gutiérrez, quiso presentarse bajo una apariencia sistemática y científica en el libro que publicó en 1900 el francés Abeille, elevando a categoría de "idioma nacional" todos los vulgarismos argentinos. (Menéndez Pidal, 1924: 21)

En su artículo, Menéndez Pidal sostiene la necesidad de mantener la unidad del castellano como "lengua culta" que se presenta como el producto de una acción colectiva, "del esfuerzo aunado de todos los espíritus cultivado y de todos los literatos insignes que se han transmitido el romance más general de 
España” (Menéndez Pidal, 1924: 16). La lengua culta opera de este modo por encima de otras variedades, que Menéndez Pidal califica como "dialectales", como una suerte de koiné en cuya formación participan hablantes cultos de las diferentes regiones del mundo de habla española, y que al mismo tiempo se presenta como una variante, en teoría, sin arraigo en un terruño específico (algo que sí sucede en cambio con las hablas "populares" o "dialectales", adopta como patrón el habla de los sectores cultos castellanos). Desde la perspectiva de Menéndez Pidal, el "gauchismo" -reivindicado por Lugones en El payador y por Rojas en la lección inaugural de la cátedra de Literatura Argentina de la Universidad de Buenos Aires- representa un elemento no de cultura popular, sino de preeminencia de lo vulgar, que "supone la mayor iniciativa del pueblo inculto": una iniciativa que caracteriza no solo a la lengua -anticipando el tipo de razonamiento que desplegará Américo Castro en La peculiaridad lingüistica rioplatense-, sino también a la literatura y la "vida entera":

Recuérdese como ejemplo, la importancia que en la literatura argentina tiene el gauchismo personificado por el Martín Fierro, y la que tiene en la misma política, personificado por Facundo Quiroga. ¿No vemos hoy a las generaciones argentinas esforzándose por combatir el gauchismo como una rémora de la cultura? (Menéndez Pidal, 1924: 19)

Como en el caso de Toro y Gisbert, aunque con menor vehemencia, Menéndez Pidal sostiene en su conferencia, que en un principio había sido pensada para una asociación de profesores de español de los Estados Unidos, la necesidad de aceptar la preeminencia normativa de la variedad castellana culta. Es algo que el sabio filólogo subraya en lo relacionado con la pronunciación ("pensando en el caso concreto de la enseñanza del español a extranjeros, no creo cabe vacilar en imponer la pronunciación de las regiones castellanas"), aunque con menor énfasis en lo que se refiere a sintaxis y vocabulario, que son precisamente las áreas en las que interviene Lugones desde Elpayador hasta sus escritos finales en los años 30. De manera coherente con los postulados españolistas de Menéndez Pidal, Tomás Navarro Tomás afirma en el artículo que recoge el mismo Cuadernillo del Instituto el carácter normativo que en la "lengua culta" debe tener la norma castellana por sobre el resto de las variedades, incluidas todas las americanas, ostensiblemente mayoritarias desde un punto de vista cuantitativo. Así, después de afirmar que "la pronunciación española correcta requiere saber distinguir entre la s y la z o la c" y de citar la Prosodia de René Bastianini (de 1914, aunque reeditada precisamente en 1924) en la que se recomienda combatir y desarraigar el yeísmo, entendido como vicio, Navarro Tomás concluye con la afirmación del carácter aparentemente no marcado desde el punto geográfico, pero si social, de la lengua literaria compartida.

Los andaluces e hispanoamericanos que adoptan en este punto la pronunciación culta española no lo hacen, pues, por evitar censuras ni molestias de ninguna clase, sino por el natural deseo de expresarse en una forma que, además de ser considerada como las más correcta, es la única que proporciona la ventaja, siempre grata, de poder alternar en España con toda clase de personas sin mostrar indicio alguno involuntario con respecto a la región o país de que cada uno procede. (Navarro Tomás, 1924: 41)

Una posición similar a la preeminencia del castellano de Madrid sobre otras variedades del español y las implicancias didácticas de esa preminencia será esgrimida por Américo Castro el 9 de febrero de 1925 desde las páginas de La Nación, y en diálogo explícito con Lugones. Lo hace en un artículo en el que retoma la iniciativa del "alto poeta", planteada en una vidriera internacional tan prestigiosa como la de la Sociedad de Naciones en Ginebra, de fundar en Madrid una institución dedicada al estudio de las lenguas románicas en paralelo, sintomáticamente, a estudios jurídicos de evidente importancia geopolítica, centrados en el derecho marítimo. Castro elogia la iniciativa de Lugones y la contrapone e un proyecto paralelo: el de fundar un Colegio Mayor en Sevilla con argumentos claramente glotopolíticos:

Posee [Sevilla] edificios suntuosos, la ciudad es bella; pero eso es todo. Quisiera aconsejar moderación y prudencia, y lo hago desde Buenos Aires porque no estoy seguro de poder hablar con esta libertad en Madrid, y teniendo además en cuenta que en esa empresa cultural van a intervenir los Gobiernos de las Repúblicas americanas. Quizá reduciendo a líneas más sobrias el proyecto se lograra algún resultado, que veo difícil de otra forma [...]. Si cada República de nuestra lengua enviara 
a Madrid pensionados, utilizando los medios que van a ponerse en juego para instaurar un Colegio Mayor, el Centro [de Estudios Históricos] organizaría una verdadera carrera de letras, a base de castellano y filología románica, lo que sería de importancia extraordinaria, incluso para mejorar aquí la enseñanza del español, ahora tan descuidada. Preciso es para ello que se abandone el proyecto de establecer en Sevilla estudios lingüísticos destinados a los pensionados de América. En primer lugar, las personas capacitadas para enseñar el castellano en forma científica se encuentran en Madrid, y luego téngase muy en cuenta que Sevilla sería un ambiente pernicioso para el estudiante de castellano, que oiría, en general, una lengua peor que la usada en las grandes ciudades de América, y no hallaría estímulo social para la enmienda. La pronunciación correcta, base de la unidad de nuestra espléndida lengua, no es en Sevilla donde puede enseñarse con más probabilidades de éxito. (Castro, 1925)

De este modo, Castro puede apoyarse en, y apropiarse de, las propuestas de Lugones para proyectar, en definitiva, una política lingüística castellanocéntrica, fuertemente españolista, en consonancia con la que esgrimen Menéndez Pidal y Navarro Tomás. Y es que, en última instancia, el objeto de la polémica central de Lugones no es el nuevo sujeto académico asociado con los filólogos españoles del Instituto de la Universidad de Buenos Aires, sino más bien las posiciones fusionales encarnadas en el proyecto estético-filológico de su estricto contemporáneo Ricardo Rojas.

Las notas de la serie euríndica, que postulan la fusión de lo autóctono y de lo europeo en una unidad trascendente, se van superponiendo, por sus tiempos de publicación y por el espacio del diario de los Mitre, con los artículos de Lugones. Una contraposición que se materializa en la publicación en dos entregas sucesivas de la sección dominical de La Nación de agosto de 1923, cuando estaban en curso de aparición las notas sobre "antecedencia arábiga", del cuento "El vaso de alabastro", de Lugones, que aparece con ilustraciones de temática y de estilo neo-egipcio de Juan Carlos Huergo, y del final de la serie de notas de Eurindia de Rojas, titulado "El símbolo del Templo", con la reproducción de un grabado de Ángel Guido en el que confluyen elementos de las culturas precolombinas y motivos coloniales europeos, incrustados en una suerte de árbol gigantesco que hunde sus raíces en la tierra americana. La pirámide es, en Lugones, la cifra de los símbolos de la patria, y la Pirámide de Mayo, "el sitio más augusto y el más alto para un argentino" (Lugones, 1919: 51), como afirma en una alocución pública en Montevideo en 1917, en plena campaña interventista. Depuración originaria, críptica, lítica y unidimensional: es la depuración inmunitara del sentido que proyecta la pirámide de los signos cuyo lenguaje oculto, cuyo jeroglífico, debe ser descifrado, en Lugones con la etimología (como forma de la semiología, desde Hegel, como ciencia general de las pirámides: Sloterdijk, 2007: 72), frente a proliferación de los sentidos, germinal y barroca, con efectos de profundidad, proyectada por Rojas.

\section{Cierre}

Paolo Virno (2003a: 31) ha insistido en la "intrínseca politicidad del lenguaje”, condición política que se hace manifiesta cuando la capacidad de producir enunciados queda, de una manera u otra, expuesta. No hay, para el pensador italiano, posibilidad de lenguaje por un lado y politicidad por el otro, sino que ambos fenómenos se identifican en una figura biopolitica que para Virno (2003b: 183) involucra la cooptación de la potencia asociada con la fuerza de trabajo. Es significativo que, en la última contribución de la serie (V. A. VIII, 5/4/1925) que estamos considerando, Lugones dedique un espacio a la voz ucumar, usual en el Noroeste, con la que se designa una figura que condensa las articulaciones entre vida, lenguaje y política. La voz designa al personaje que "extraviado en la infancia, habría perdido el uso de la palabra y solo aparecía, a la noche, acuciado por el hambre y la sed". Para explicar el término que designa la figura, Lugones recurre previsiblemente al árabe ugumar, "duende" o "fantasma", registrado en el Vocabulario arbigo de Alcalá de 1505. Se trata de una figura "al bando", de una figura eminentemente política. Es en la distancia quebradiza entre silencio -como potencia de hablar y de producir- y lenguas históricas donde se pone en juego la dimensión que articula vida, política y lenguaje (Agamben, 2001). 
El silencio del "ucumar" es una figura paradigmática que convoca la crisis o in-fancia (Virno, 2003a: 169) en que el hipotético "poder decir" se manifiesta como potencia y es llenado por la acción etimológica lugoniana: una acción que sutura la "voz", en su acepción de vocablo, a un colectivo lingüístico prestigioso. Y que, al mismo tiempo, le otorga una "voz" a los habitantes de la América indígena.

Ángel Rama sostiene que el esfuerzo de interpretación de los escritores modernistas "no se orienta ya hacia los objetos concretos e individuales, sino hacia los instrumentos con que se fabrican los objetos culturales" (Rama, 1985. 192). Se orientan, en primer lugar, hacia la lengua. Si en la década del veinte, en ámbitos como el de las grandes islas de habla castellana del Caribe, un filólogo formado en la escuela pidaliana como Pedro Henríquez Ureña opera un "emblanquecimiento" del español de la región y un ocultamiento de la matriz negra africana (Valdez, 2015: 226 y ss.), en un ámbito geopolítico como el del Cono Sur, en el que la lucha contra los indígenas de la Pampa y la Patagonia y de la región del Chaco era un proceso reciente ( $y$, en esta última zona, todavía en curso), intelectuales como Lugones ponen en marcha un proceso similar de purificación de la lengua. En efecto, a través de sus notas etimológicas, Lugones intentaba purificar con el corte etimológico la lengua del "indio, mudo" del que hablaba José Martí (1973: 79) en las páginas de "Nuestra América". Filiarlo en una palabra legítima y, mediante ese gesto, incorporarlo al ámbito de una lengua prestigiosa -depurada de americanismos y de indianismos- para su "patria fuerte".

\section{REFERENCIAS}

Agamben, G. (2001). Lo que queda de Auschwitz. El archivo y el testigo. Valencia: Pre-Textos.

Angenot, M. (1981). La parole pamphlétaire. Typologie des discours modernes. París: Payot.

Angenot, M. (2010). Interdiscursividades. De hegemonias y disidencias. Córdoba: Editorial Universidad Nacional de Córdoba.

Anónimo (1925). D. Ramón del Valle Inclán habla del futuro idioma argentino. En La Nación, Buenos Aires, 18 de marzo.

Arnoux, E. y Nothstein, S. (eds.) (2014). Temas de glotopolitica. Integración regional sudamericana y panhispanismo. Buenos Aires: Biblos.

Badiou, A. (2005). El siglo. Buenos Aires: Manantial.

Bentivegna, D. (2011). El poder de la letra. Literatura y domesticación en la Argentina. La Plata: Unipe.

Bentivegna, D. (2018). Formar la lengua. Etimología, patria y lenguaje en El payador de Leopoldo Lugones, Interpretatio. Revista de Hermenéutica, n. 1, México, Universidad Nacional Autónoma. En prensa.

Bombini, G. (2004). Los arrabales de la literatura. La historia de la enseñanza literaria en la escuela secundaria argentina. Buenos Aires: Miño y Dávila.

Borges, J. L. (1960). Otras inquisiciones. Buenos Aires: Emecé.

Cacciari, M. (1994). Geofilosofia dell'Europa. Milán: Adelphi.

Caeiro, O. (1975). Lugones y Nietzsche, Criterio, Buenos Aires, n. 1715, 233-241.

Castro, A. (1924a). ¿Dialecto argentino?. En La Nación, Buenos Aires, 20 de abril.

Castro, A. (1924b). Sobre dialecto argentino. En La Nación, Buenos Aires, 30 de abril.

Castro, A. (1924c). Introducción. Instituto de Filologia, Tomo I, Cuaderno I. Buenos Aires, Juan Roldán. 7-11.

Castro, A. (1925). El colegio Mayor de Sevilla y la iniciativa de Lugones. En La Nación, Buenos Aires, 9 de febrero.

Castro-Gómez, S. (1996). Crítica de la razón americana. Barcelona: Puvill libros.

Conil Paz, A. (1985). Leopoldo Lugones. Buenos Aires: Huemul.

Dalmaroni, M. (2006). Una república de las letras. Lugones, Rojas, Payró. Escritores argentinos y Estado. Buenos Aires: Beatriz Viterbo. 
Dobry, E. (2010). Una profecia del pasado. Lugones y la invención del "linaje de Hércules", Buenos Aires: Fondo de Cultura Económica.

Degiovanni, F. y Toscano, G. (2010). Disputas de origen: Américo Castro y la institucionalización de la filología en la Argentina, Nueva Revista de Filología Hispánica, México, vol. LVIII, n. 1, 191-214.

Del Valle, J. (1998). Andalucismo, poligénesis y koineización: dialectología e ideología. Hispanic Review, 66, 2, 132-149.

Del Valle, J. (2004). Menéndez Pidal, la regeneración nacional y la utopía lingüística. En J. del Valle y L. GabrielStheeman (eds.), La batalla del idioma. La intelectualidad hispánica ante la lengua. Frankfurt: VervuertIberoamericana, 109-135.

Del Valle, J. (ed.) (2015). Historia politica del español. La creación de una lengua. Madrid: Aluvión.

Diccionario del habla de los argentinos (2008). Buenos Aires: Academia Argentina de Letras.

Ennis, J. A. y Pfänder, S. (2013). Lo criollo en cuestión. Filología e historia. Buenos Aires: Katatay.

Esposito, R. (2005). Immunitas. Protección y negación de la vida. Buenos Aires: Amorrortu.

Esposito, R. (2009a). Comunidad y violencia. Madrid: Círculo de Bellas Artes. Recuperado de: http://www.circulobe llasartes.com/fich_minerva_articulos/Comunidad_y_violencia_\%287392\%29.pdf.

Esposito, R. (2009b). Tercera persona. Politica de la vida y filosofía de lo impersonal. Buenos Aires: Amorrortu.

Esposito, R. (2015). Pensamiento viviente. Origen y actualidad de la filosofia italiana. Buenos Aires: Amorrortu.

Foucault, M. (1992). Microfísica del poder. Madrid: La Piqueta.

Garzón, T. (1910). Diccionario argentino. Barcelona: Borrás y Mestres.

Gramsci, A. (2013). Escritos sobre el lenguaje. Buenos Aires: Eduntref.

Granada, D. (1890). Vocabulario rioplatense razonado. Montevideo: Imprenta Rural.

Greimas, A. (1976). Semiótica do discurso cientifico. Da modalidade. San Pablo: Difel.

Groussac, P. (1904). A propósito de americanismos. En El viaje intelectual. Primera serie. Madrid: Victorino Suárez, 383-429.

Groussac, P. (1924). Sobre cuestiones de filología americana. En La Nación, Buenos Aires, 14 de mayo.

Lafone y Quevedo, S. (1898). Tesoro de catamarqueñismos. Buenos Aires: Coni.

Lenz, R. (1910). Diccionario etimolojico de las voces chilenas derivadas de las lenguas indijenas americanas. Santiago de Chile: Imprenta Cervantes.

Lope Blanch, J. M. (2008). El español americano. México: El Colegio de México.

Lugones, L. (1919). La torre de Casandra. Buenos Aires: Atlántida.

Lugones, L. (1922). El canto primero de la Ilíada. En La Nación, Buenos Aires, 28 de mayo.

Lugones, L. (1923 $)$. Voces americanas de antecedencia griega I. En La Nación, Buenos Aires, 14 de enero.

Lugones, L. (1923b). Voces americanas de antecedencia griega II. En La Nación, Buenos Aires, 18 de febrero.

Lugones, L. (1923c). Voces argentinas de procedencia arábiga I. En La Nación, Buenos Aires, 4 de marzo.

Lugones, L. (1923d). Voces americanas de procedencia arábiga II. En La Nación, Buenos Aires, 25 de marzo.

Lugones, L. (1923e). Voces americanas de procedencia arábiga III. En La Nación, Buenos Aires, 29 de abril.

Lugones, L. (1924a). Voces americanas de procedencia arábiga IV. En La Nación, Buenos Aires, 24 de febrero.

Lugones, L. (1924b). Voces americanas de procedencia arábiga V. En La Nación, 9 de marzo.

Lugones, L. (1924c). Algo respecto a indianismos. En La Nación, Buenos Aires, 11 de mayo.

Lugones, L. (1924d). Voces americanas de procedencia arábiga VI. En La Nación, Buenos Aires, 1 ro. de junio.

Lugones, L. (1925a). Voces americanas de procedencia arábiga VII. En La Nación, Buenos Aires, 1 de marzo.

Lugones, L. (1925b). Voces americanas de procedencia arábiga VIII. En La Nación, Buenos Aires, 5 de abril.

Lugones, L. (1930). La patria fuerte. Buenos Aires: Círculo Militar.

Lugones, L. (1944). Diccionario etimológico del castellano usual. Buenos Aires: Academia Argentina de Letras. 
Lugones, L. (1961). El payador. Buenos Aires: Centurión.

Maingueneau, D. (1984). Genèses du discours. Bruselas: Pierre Mardaga.

Martí, J. (1973). Páginas escogidas. Ed. de Benito Varela Jacome. Barcelona: Bruguera.

Menéndez Pidal, R. (1924). La lengua española. En Instituto de Filología. Tomo I. Cuaderno I. Buenos Aires: Juan Roldán. 15-27.

Moreno Cabrera, J. C. (2014). El nacionalismo lingüistico. Una ideología destructiva. Barcelona: Península.

Navarro Tomás, T. (1924). Concepto de pronunciación correcta. En Instituto de Filología. Tomo I. Cuaderno I. Buenos Aires: Juan Roldán. 31-41.

Olender, M. (2005). Las lenguas del Paraíso. México: Fondo de Cultura Económica.

Peña, A. (1973). Américo Castro y su visión de España y de Cervantes. Madrid: Gredos.

Pultera, R. (1956). Lugones. Elementos cardinales destinados a determinar una biografia. Buenos Aires: s/e.

Rama, Á. (1985). Las máscaras democráticas del modernismo. Montevideo: Fundación Ángel Rama.

Rama, Á. (2004). La ciudad letrada. Santiago de Chile: Tajamar.

Ramos, J. (1996). Paradojas de la letra. Caracas: eXcultura - Universidad Simón Bolívar.

Rodríguez Pérsico, A. (2006). El lugar (del) secreto: Leopoldo Lugones y las figuras de escritor, Cuadernos LI. RI. CO. Revista de la red interuniversitaria de estudios sobre las literaturas rioplatenses contemporáneas en Francia, año I, n. 1.39-58.

Rojas, R. (1992). Eurindia. Buenos Aires: Centro Editor de América Latina.

Toro y Gisbert, M. (1912). Americanismos. París: Librería Paul Ollendorff.

Segovia, L. (1911). Diccionario de argentinismos, neologismos y barbarismos. Buenos Aires: Coni.

Said, E. W. (2004). El mundo, el texto y el critico. Barcelona: Debate.

Sloterdijk, P. (2007). Derrida, un egipcio. Buenos Aires: Amorrortu.

Valdez, J. (2015). En busca de la identidad. La obra de Pedro Henríquez Ureña, Buenos Aires: Katatay.

Virno, P. (2003a). Il verbo si fa carne. Linguaggio e natura umana. Turín: Bollati Boringhieri.

Virno, P. (2003b). Gramática de la multitud. Madrid: Traficantes de sueños.

Wagner, M. L. (1924). El español de América y el latín vulgar. En Instituto de Filología. Tomo I. Cuaderno I. Buenos Aires: Juan Roldán. 45-110.

\section{Notas}

1 Para Menéndez Pidal y la construcción discursiva del hispanismo, cfr. José del Valle (2004).

2 El texto de la alocución fue incluido por Lugones en 1930, el mismo año del golpe de Estado contra Hipólito Yirigoyen, en La patria fuerte.

3 "La circunstancia de haber sido la quichua en Santiago lengua corriente hasta pocos años ha, y más difundida que el castellano, sobre todo en la campaña, motiva la atribución frecuente al idioma americano, de cuanta voz parece extraña al castellano usual o académico....", (Lugones, 1923b).

4 Es lo que en el Diccionario Lugones denominará "concurrencia radical o agregación confluente, tal cual sucede con la mezcla de sangres en los pueblos de análoga formación” (Lugones, 1944: 8).

5 "Al concluirse la Semana de Mayo, entrego como patriótico homenaje, vertido hexámetro a hexámetro, en los mismos seiscientos once versos del original, el Canto I de la Ilíada” (Lugones 1922). El guiño helenizante se repite al año siguiente, el 24 de mayo de 1923 Lugones publica, como conmemoración: del 25 de mayo, la traducción de un fragmento del Canto V del poema homérico, dedicado a las hazañas de Diomedes.

6 Por ejemplo, en la última entrega de la serie dedicada a procedencias arábigas, Lugones reconoce que la filiación griega que había dado a la voz vincha era errada, y se inclina no por supuesto por reponer la correcta filiación americana, sino por la arábiga. Para ello debe postular un desplazamiento del sentido: "Las mujeres árabes de Siria y del Cairo usaban como adorno de cabeza una especie de mitra o gorro cónico de cartón dorado, pintado, chapado de plata, y a veces formado por una hoja de este mismo material: tocado que recibía en ambas comarcas el nombre de "finschán” y de cuya punta colgaba 
a veces un velo. Llevado quizá por las mujeres de la España musulmana, donde solían reinar las modas de Siria y Egipto, daría su nombre a las diademas de adorno y su origen al "hennin" francés que era un atavío idéntico" (Lugones, 1924c)

7 Para una discusión en torno a este concepto, cfr. J. M. Lope Blanch (2008).

8 Así, por ejemplo, la voz virque, corriente en Santiago como designación de una cazuela grande usada en ocasiones como brasero, es exactamente el mismo que en griego. Lo mismo sucede con muchas voces latinas y griegas, que permanecen "intactas" en América y han sido olvidadas o corrompidas en España, por lo que "El estudio de nuestro castellano adquiere, así, una importancia filológica descollante en el mundo entero" (Lugones, 1922b).

9 El término resulta de etimología en el Vocabulario de Lenz, quien rechaza de manera explícita la derivación "pampa" propuesta por Granada y conjetura una posible derivación guaraní. Cfr. Lenz, (1910: 62).

10 Massimo Cacciari (1994: 107), a su vez, ha insistido en las conexiones schmittianas entre corte y decisión política

11 Un eco de los postulados de Lugones se escuchará años más tarde en la refutación que Borges esgrime, precisamente, contra las posturas de Castro: "No adolecemos de dialectos, pero sí de institutos dialectológicos" (Borges, 1960: 31). Estamos en ambos casos, Borges y Lugones, desde posturas letradas que desdeñan el componente indígena, ante posiciones que no perciben el carácter dialectal complejo de la realidad lingüística (argentina y de cualquier otro país), que la lectura de Lenz, indudablemente, habría permitido, al menos, matizar. Para los usos ideológicos de la oposición “lengua” versus “dialecto", cfr. Moreno Cabrera (2014: 45).

12 Para Groussac, la cuestión que se dirime en torno a la etimología de vocablos como “chancho” o "bagual” es una cuestión de alcance epistemológico. En efecto, su intervención concluye: "sin la sinceridad en el estudio y la probidad absoluta en la cita de las fuentes informativas no existe verdadera eficacia científica, sino falta de saber de superficie y relumbrón. // Saludo atentamente al señor director" (Groussac, 1924). 